\title{
Electric and chemical fusions for the production of monoclonal antibodies reacting with the in-vivo growth phase of Candida albicans
}

\author{
B. FORTIER, VALERIE HOPWOOD* and D.POULAIN $\dagger$
}

\begin{abstract}
Unité 42 de Biologie et de Biochimie Parasitaires et Fongiques de I'Institut National de la Santé et de la Recherche Médicale, Domaine du Certia, 59650 Villeneuve D'Ascq, France
\end{abstract}

\begin{abstract}
Summary. To obtain monoclonal antibodies (MAbs) directed preferentially against the pathogenic phase of Candida albicans, mice were immunised with germ tubes of C. albicans serotype A, strain VW.32, killed by exposure to ultraviolet (UV) irradiation. Fusions were performed either by the standard chemical procedure with polyethylene glycol, or by electric discharge following linkage of the myeloma and lymphocyte cells with a Concanavalin A-mannoprotein bridge. The preliminary characteristics of one MAb obtained from each of these fusions are described. An IgM antibody (3B7) obtained from the chemical fusion reacted with a polysaccharide antigen that was heterogeneously distributed on both in-vitro and in-vivo forms of $C$. albicans. This MAb agglutinated different strains of $C$. albicans irrespective of their serotype. An $\mathrm{IgG}_{1}$ antibody (3G6) that had been obtained from the electric fusion was found to react in vitro with a proteinaceous antigen located only on the germ tubes of strain VW.32. However, MAb 3G6 displayed strong reactivity against all growth forms of $C$. albicans in vivo and reactivity extended to other strains.
\end{abstract}

\section{Introduction}

There have been numerous reports describing monoclonal antibodies (MAbs) produced against the pathogenic yeast Candida albicans (Brawner and Cutler, 1984; Strockbine et al., 1984; Barbier et al., 1985; Chardes et al., 1986; Hopwood et al., 1986; Miyakawa et al., 1986; Polonelli and Morace, 1986; Reiss et al., 1986). These MAbs were produced following immunisation of mice with heat-killed or formol-inactivated whole blastospores (Brawner and Cutler, 1984; Chardes et al., 1986), or protein (Strockbine et al., 1984), or polysaccharide (Miyakawa et al., 1986, Reiss et al., 1986) antigens extracted from blastospores. Taking into account the antigenic variability of $C$. albicans and the possible relationship between antigen expression and pathogenicity (Poulain et al., 1983), attempts have also been made to produce MAbs against the pathogenic phase of $C$. albicans (Hopwood et al., 1986). Because of the difficulty of inducing an immune response in mice following experimental infection (Winterrowd and Cutler,

Received 26 Nov. 1987; accepted 20 May 1988.

* Present address: Department of Microbiology, Bristol Royal Infirmary, Bristol BS2 $8 \mathrm{HW}$.

† Correspondence should be sent to Dr D. Poulain.
1983; Hopwood et al., 1986), in this study mice were immunised with growth forms of C. albicans obtained in vitro that were closely related morphologically to the pathogenic phase. Non-viable germ tubes were used as the immunogen because this growth form more closely resembles that found in vivo than blastospores (Odds, 1985). Germ tubes have also been shown to be more reactive than blastospores against sera from patients infected with C. albicans (Poulain et al., 1983) and to possess specific antigens (Smail and Jones, 1984; Sundstrom and Kenny, 1984). To preserve the integrity of thermolabile antigens and to minimise antigen denaturation following aldehyde fixation, the germ tubes were killed by UV irradiation.

The major antigenic components of Candida spp. are mannoproteins (Ballou, 1976; Poulain et al., 1985). Concanavalin A (Con A) binds to the polysaccharide components of these molecules (Ballou, 1976) and has also been shown to bind to myelocyte membranes (Monsigny et al., 1978). In this study we favoured fusing myeloma cells with selected $\mathbf{B}$ lymphocytes secreting antibodies against C. albicans by linking the two cell types with Con A before exposure to an electrical discharge. The lymphocytes were preselected by their ability to bind purified mannoproteins. 
The electric and chemical methods employed to fuse the cells resulted in 12 hybridomas secreting antibodies to Candida spp. We describe the preliminary characteristics of one MAb from each of these fusions, that reacted strongly with the in-vivo growth phase of $C$. albicans.

\section{Materials and methods}

\section{Strains and culture conditions}

For antibody production we used a cloned strain of $C$. albicans serotype A (VW.32) that had been previously employed to produce MAbs (Hopwood et al., 1986). This strain was selected for its high reactivity against sera from patients and animals infected with C. albicans and was previously defined as being rich in $\mathbf{P}$ antigens (quantitatively and/or qualitatively variable antigens expressed preferentially by the pathogenic phase) (Poulain et al., 1983). The reference strains used for studying the distribution of the antigens recognised by the MAbs consisted of five $C$. albicans strains, serotype A or B, and seven Candida spp. other than C. albicans (tables I and II). The origin of these strains and their serological reactivities against polyclonal and monoclonal antibodies were described by Poulain et al. (1983) and Hopwood et al. (1986).

Blastospores for screening were obtained by culture on Sabouraud Dextrose Agar (SDA) for $24 \mathrm{~h}$ at $37^{\circ} \mathrm{C}$. C. albicans blastospores were washed twice in phosphate-

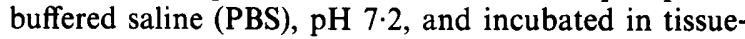
culture medium 199 (Eurotroph; Eurobio, Paris, France) for $2.5 \mathrm{~h}$ at $37^{\circ} \mathrm{C}$, with continual stirring, for the production of germ tubes.

\section{Immunisation of animals}

Eight-week-old BALB/c mice (Iffa Credo, France) were inoculated intraperitoneally six times a week with $0.4 \mathrm{ml}$ of a suspension of UV-killed $C$. albicans strain VW.32 germ tubes $\left(10^{7} / \mathrm{ml}\right.$ in physiological saline) for 6 weeks. The absence of viable germ tubes was determined by culture on SDA for $48 \mathrm{~h}$ at $37^{\circ} \mathrm{C}$. Mice were bled weekly from the orbital sinus, and the serum was assayed for antibody production by immunofluorescence (IF) (see below). At the end of the sixth week, mice producing antibodies were rested for 7 days and then given a booster injection of $4 \times 10^{6}$ germ tubes intravenously. Spleens were removed for fusion three days after the booster injection.

\section{Hybridoma production}

Murine myeloma cell line SP2/0 was cultured in Dulbecco Modified Eagle's Medium (DMEM)(Seromed, Strasbourg, France) supplemented with fetal calf serum $10 \%$, non-essential amino acids, glutamine, pyruvate and gentamicin (Galfre et al., 1977) (medium A).

Fusion of spleen cells from immunised animals with myeloma cells was performed either by the standard chemical procedure of Galfre et al. (1977) with polyethylene glycol (PEG) or by a modification of the electricfusion procedure described by Lo et al. (1984). Both fusion techniques were used for cells from the same spleen.

Electric fusion. The principle of this fusion procedure is schematised in fig. 1. Preparation of myeloma and spleen cells was performed at $4^{\circ} \mathrm{C}$. Myeloma cells were washed twice in PBS, pH 7.4, supplemented with $1 \mathrm{mM}$ $\mathrm{CaCl}_{2}$ and $1 \mathrm{mM} \mathrm{MgSO}_{4}$ (PBS-CM). The cells $\left(10^{6} / \mathrm{ml}\right)$ were then suspended in a solution of Con A $0 \cdot 1 \mu \mathrm{g} / \mathrm{ml}$ (IBF, Villeneuve la Garenne, France) in PBS-CM, incubated for $1 \mathrm{~h}$ and washed twice in PBS-CM.

A suspension of spleen cells was prepared by gentle homogenisation of the spleen in PBS-CM and the splenocytes were then washed twice in PBS-CM. The cells were next incubated for $1 \mathrm{~h}$ in PBS-CM containing mannoproteins prepared from C. albicans, $10 \mu \mathrm{g} / \mathrm{ml}$. Mannoproteins were prepared by heating blastospores for $2 \mathrm{~h}$ at $134^{\circ} \mathrm{C}$ in $19 \mathrm{~mm}$ citrate buffer (Peat et al., 1961). The extract was then made up to molar concentration

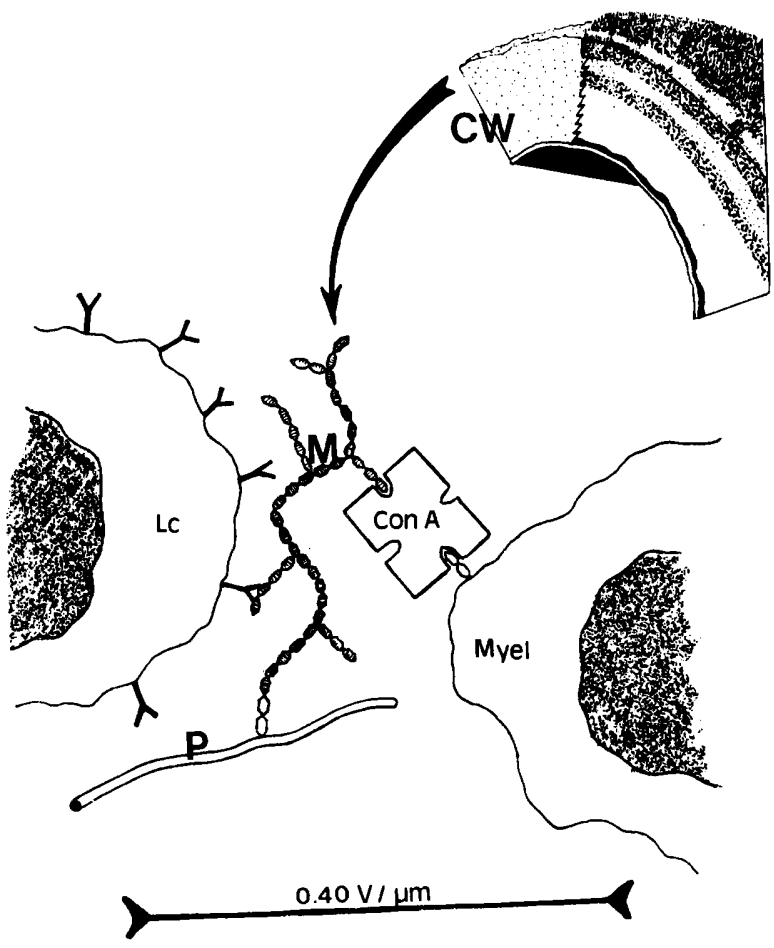

Fig. 1. Hypothesis for the possible mechanism of linkage between B lymphocytes (Lc) and myeloma cells (Myel) via Con A-mannan bridges established before electric fusion. Mannoproteins extracted from the cell wall $(\mathrm{CW})$ of $C$. albicans react via their polysaccharide side chains, namely the mannans $(\mathrm{M})$, with both Con $A$ and surface bound anti-candida immunoglobulins. Linkage with the lymphocytes may be established via either the polysaccharide side chains or the protein moiety (P) depending on the specificity of the surface-bound antibodies (to simplify the scheme only a few of the mannan side chains are represented in the figure). 
with acetic acid, neutralised with $6 \mathrm{M} \mathrm{NaOH}$, precipitated with ethanol, redissolved in water, dialysed and lyophilised. Protein content (Pierce BCA protein assay reagent) of the extract was $400 \mathrm{mg}$ of protein/g dried weight. After washing the spleen cells twice in PBS-CM, the myeloma and spleen cells were mixed in a ratio of $1: 1$, centrifuged for $10 \mathrm{~min}$ at $700 \mathrm{~g}$, and the pellet was resuspended in $272 \mathrm{~mm}$ sucrose in $7 \mathrm{~mm}$ PBS, pH $7 \cdot 2$, containing $1 \mathrm{~mm}$ $\mathrm{MgSO}_{4}$ (Teissie et al., 1982) at a density of $4 \times 10^{7}$ cells/ $\mathrm{ml}$. The electric fusion was performed in a sterile chamber made by fixing two stainless-steel razor blades parallel to each other, $3 \mathrm{~mm}$ apart (Teissie et al., 1982); $200 \mu \mathrm{l}$ of cell suspension were deposited between the two blades and three electric pulses were then generated with 4-s delay between pulses, by discharge of a $1 \mu \mathrm{F}$ condensor into the blades so that the field strength was $4 \mathrm{kV} / \mathrm{cm}$ at the beginning of discharge (half charge duration $20 \mu \mathrm{s}$ ). At the end of electric pulsing the cells were gently aspirated, suspended in medium $\mathrm{A}$ at $37^{\circ} \mathrm{C}$ and dispensed into the wells of 96 -well microtitration plates $\left(7 \times 10^{4}\right.$ cells/well) containing $3 \times 10^{3}$ peritoneal cells/well as a feeder layer.

After incubation at $37^{\circ} \mathrm{C}$ for $18 \mathrm{~h}$, hypoxanthine, aminopterin and thymidine were added to select for hybrid cells (Galfre et al., 1977). Positive hybrids were subcloned twice by limiting dilution.

Chemical fusion. Fusion was performed by the method of Galfre et al. (1977). Briefly, spleen cells $\left(7 \times 10^{7}\right)$ were fused with myeloma cells $\left(1.4 \times 10^{7}\right)$ with polyethylene glycol 1500 (PEG) $35 \%$ in DMEM. The cell suspension in medium $\mathrm{A}$ was seeded in microtitration plate wells $\left(3 \times 10^{4}\right.$ cells/well) containing $3 \times 10^{3}$ peritoneal cells as a feeder layer. After $18 \mathrm{~h}$, hypoxanthine, aminopterin and thymidine were added to select for hybrid cells. Positive hybrids were subcloned twice by limiting dilution.

\section{Screening for $M A b$ reactivity}

Preliminary screening for antibody secretion was performed by immunofluorescence (IF), with strain VW. 32 germ tubes as the antigen, as described previously (Hopwood et al., 1986). Commercial fluorescein conjugated anti-mouse immunoglobulins (Zymed, Biosoft, Paris, France; Nordic, Tebu, Versailles, France) were used at dilutions ranging from 1 in 40 to 1 in 100 . Supernates from wells that gave positive results in the screening were tested further with a range of candida antigens to determine the distribution of the epitope recognised, and for preliminary characterisation of the antigenic molecules.

\section{Determination of the $M A b$ reactivity}

Immunofluorescence (IF) reactions were performed with treated or untreated in-vitro and in-vivo growth forms of the reference yeast species. In-vitro blastospores and germ tubes were obtained from the strains listed in tables I and II as described above for strain VW. 32 .

The germ tubes of strain VW.32 were subjected to various physico-chemical treatments for antigen extrac- tion or denaturation. These methods were described in detail by Hopwood et al. (1986). Briefly, cells were heat treated for various periods of time $-56^{\circ} \mathrm{C}$ for $30 \mathrm{~min}$, $80^{\circ} \mathrm{C}$ for $10 \mathrm{~min}$, or $134^{\circ} \mathrm{C}$ for $2 \mathrm{~h}$. Enzymic treatment consisted of incubation in PBS with $2.5 \mathrm{mg} / \mathrm{ml}$ of the following enzymes; pronase, trypsin, or chymotrypsin, for periods ranging from $3 \mathrm{~h}$ to $24 \mathrm{~h}$.

IF with in-vivo growth forms was performed on cryostat sections prepared from kidneys of rabbits infected with strain VW.32 or strain 996 B as described previously (Hopwood et al., 1986).

Direct agglutination was performed by mixing $20 \mu \mathrm{l}$ of hybridoma supernate with $20 \mu \mathrm{l}$ of a suspension of glutaraldehyde-fixed blastospores $\left(10^{8}\right.$ cells $\left./ \mathrm{ml}\right)$ (Hopwood et al., 1986). Agglutination was recorded macroscopically after agitation for $2 \mathrm{~min}$ on a Kline agitator.

Precipitating activity of the MAbs was determined by counterimmunoelectrophoresis (CIE) on cellulose acetate membranes against a somatic antigen of strain VW.32 as described by Poulain et al. (1986).

\section{Nature of MAbs and production of ascites}

Isotypes were determined with class and sub-class specific antibodies in IF reactions and confirmed by immunodiffusion with class and sub-class specific antibodies (Zymed, Biosoft, Paris, France; Nordic, Tebu, Versailles, France).

Ascitic fluid was prepared from BALB/c mice pretreated with pristane $(0.5 \mathrm{ml})$ and inoculated with $10^{6}$ hybridoma cells.

\section{Results}

\section{Electric fusion}

Twenty five hybridomas were obtained of which six secreted antibodies reacting with $C$. albicans. As the reactivity of these six clones against the various Candida strains appeared to be identical, we have chosen to describe only one of them, named 3G6, here.

This mouse $\mathrm{IgG}_{1} \mathrm{MAb}$ reacted in IF with the homologous antigen producing a fluorescent reaction located on the germ tubes. Mother blastospores were unlabelled (fig. 2a). None of the germ tubes or blastospores produced in vitro by the other strains of $C$. albicans tested was labelled (fig. 2b); neither were blastospores of other yeast species (table I).

When IF reactions were performed on in-vivo growth forms of $C$. albicans, the homologous strain VW.32 and also strain 996B, which gave completely negative results in vitro, exhibited strong reactivity (fig. 2c). This reactivity was located on both the blastospores and hyphal forms. Physico-chemical treatment demonstrated the heat lability of the 

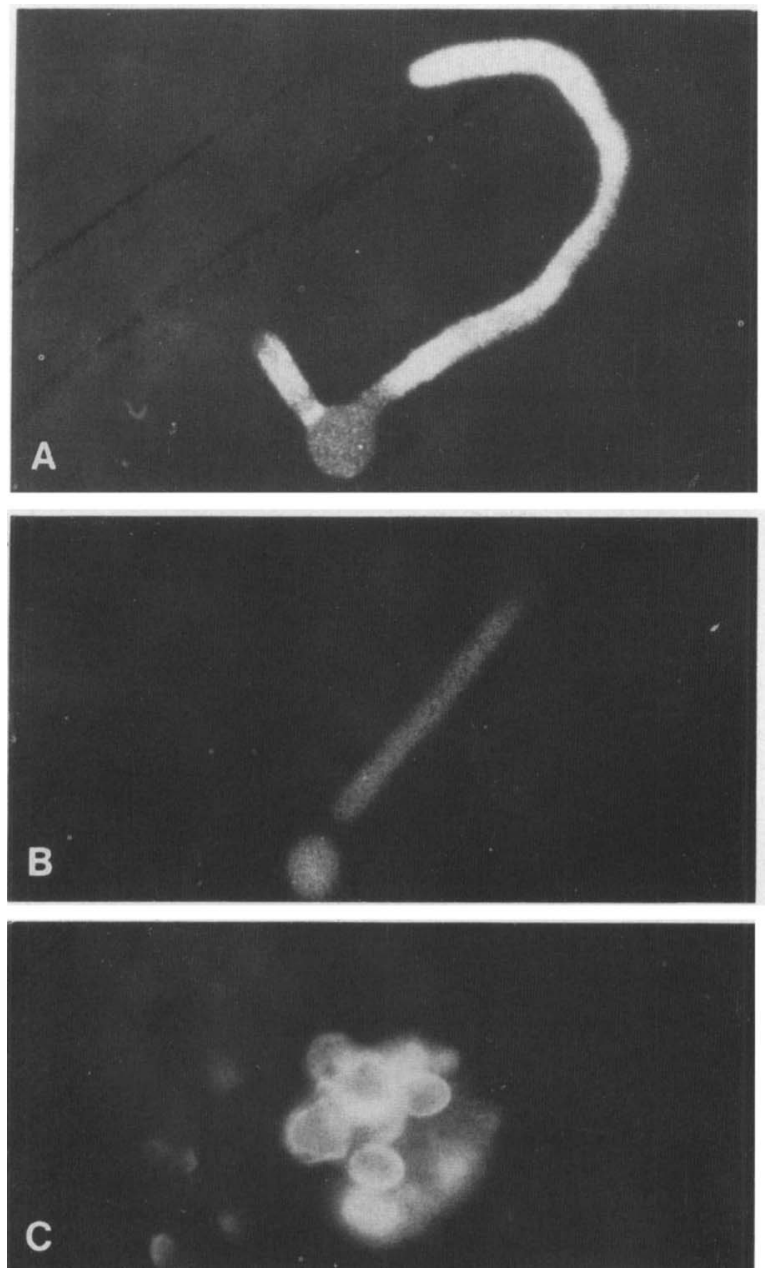

Fig. 2. Reaction of MAb 3G6 against $C$. albicans by indirect immunofluorescence. a. Germ tubes of strain VW.32 obtained in medium 199. The fluorescence is distributed over the whole surface of the germ tube whereas the mother blastospore is completely unlabelled. b. Germ tubes of strain $996 \mathrm{~B}$ obtained in medium 199. Both the germ tubes and mother blastospore are unlabelled. c. In-vivo growth form of strain 996B in sections from infected rabbit kidneys. Strong fluorescence is apparent on all fungal elements.

antigens on VW.32 germ tubes, recognised by the reactions with MAb $3 \mathrm{G} 6$ as well as by their susceptibility to proteolytic digestion (table I). Under the experimental conditions described here we were unable to demonstrate any agglutinating or precipitating activity of this MAb.

\section{Chemical fusion}

The chemical fusion resulted in six hybridomas which secreted antibodies reacting with C. albicans.
However, there was variation in the reactivity of these antibodies against the various Candida strains and growth forms in IF reactions. We report here the properties of one of these antibodies, an $\operatorname{IgM}(\kappa$ chain), referred to as $3 \mathrm{~B} 7$. The reactivity of $\mathrm{MAb}$ $3 B 7$ against the different candida antigens is summarised in table II.

MAb 3B7 reacted in IF with cells of the homologous strain VW.32 with fluorescence usually distributed on the germ tubes and on mother blastospores. However, a proportion of the blastospores was unlabelled. This is referred to as a mosaic reaction. The proportion of unlabelled blastospores was greater when they were grown on SDA than when they were incubated in medium 199. Mosaic reactions were observed on either the germ tubes or on the blastospores of the other $C$. albicans strains tested. One strain of $C$. albicans serotype A (995A) was completely devoid of reactivity; this absence of reactivity was confirmed by direct agglutination (table II). The in-vivo growth forms of the two strains tested (VW.32 and 996B) were highly reactive.

The antigen recognised by $\mathrm{MAb} 3 \mathrm{~B} 7$ was resistant to all of the physico-chemical treatments used, except for autoclaving. The antigen was also present in a somatic antigen extract prepared from blastospores of strain VW.32 as demonstrated by the precipitin line observed when MAb 3B7 was allowed to react with the extract in CIE.

\section{Discussion}

Our ability to produce hybridomas which secrete antibodies to $C$. albicans following electric fusion demonstrates the success of this procedure and its potential as an alternative method to PEG for the production of MAbs. Prior incubation of the lymphocytes from the immunised mice with $C$. albicans mannoproteins contributed to the establishment of linkages between the lymphocytes and the myeloma cells preincubated in Con A, although the possibility of a direct linkage between myeloma and lymphocyte membranes with Con A cannot be excluded (Monsigny et al., 1978).

However, the fact that all of the six MAbs obtained had the same specificity suggests that the former unique procedure for selecting the lymphocytes with mannoprotein had indeed occurred. A possible mechanism for linkage with the mannan portion of mannoproteins is schematised in fig. 1. The apparent specificity of the reactions of MAb 3G6 against protein antigens, however, does not seem to be compatible with the theory that linkage 
Table I. Reactivity of MAb 3G6 against in-vitro and in-vivo growth forms of Candida spp. by IF, direct agglutination and CIE

\begin{tabular}{|c|c|c|c|c|c|c|c|c|}
\hline & \multirow[b]{4}{*}{ Yeast antigens } & & \multicolumn{4}{|c|}{ Immunofluorescence reaction } & \multirow{3}{*}{\multicolumn{2}{|c|}{ Reaction by }} \\
\hline & & & \multicolumn{3}{|c|}{ in-vitro form } & \multirow{3}{*}{$\begin{array}{c}\text { in-vivo form } \\
\text { blastoconidia } \\
\text { and } \\
\text { hyphae }\end{array}$} & & \\
\hline & & & \multicolumn{2}{|c|}{ Blastoconidia* } & \multirow{2}{*}{ germ-tubes } & & & \\
\hline & & & $\mathrm{s}$ & 199 & & & $\begin{array}{c}\text { direct } \\
\text { agglutination }\end{array}$ & $\begin{array}{l}\text { precipitation } \\
\text { (CIE) }\end{array}$ \\
\hline \multirow{4}{*}{$\begin{array}{l}\text { C. albicans } \\
\text { strain V }\end{array}$} & W 33 (untreated) & & & & & & & \\
\hline & $30 \mathrm{~min} 56^{\circ} \mathrm{C}$ & & - & - & ++ & +++ & - & - \\
\hline & $10 \mathrm{~min} 80^{\circ} \mathrm{C}$ & & - & - & $\begin{array}{l}- \\
-\end{array}$ & $\begin{array}{l}\cdots \\
\ldots\end{array}$ & $\cdots$ & $\cdots$ \\
\hline & $2 \mathrm{~h} 134^{\circ} \mathrm{C}$ & & - & - & - & $\ldots$ & $\ldots$ & $\ldots$ \\
\hline \multirow[t]{3}{*}{ treated } & Pronase & $3 \mathrm{~h} / 24 \mathrm{~h}$ & - & - & - & $\ldots$ & $\ldots$ & $\ldots$ \\
\hline & Trypsin & $3 \mathrm{~h} / 24 \mathrm{~h}$ & - & - & $+/ \pm$ & $\ldots$ & $\ldots$ & $\ldots$ \\
\hline & $\begin{array}{l}\text { Chymotryp- } \\
\text { sin }\end{array}$ & $3 \mathrm{~h} / 24 \mathrm{~h}$ & - & - & $+/ \pm$ & $\cdots$ & $\ldots$ & ... \\
\hline \multicolumn{2}{|c|}{ strain $995 \mathrm{~A}$} & & - & - & - & $\ldots$ & - & $\ldots$ \\
\hline \multirow{2}{*}{\multicolumn{2}{|c|}{$\begin{array}{l}\text { strain } 3153 \mathrm{~A} \\
\text { strain } 996 \mathrm{~B}\end{array}$}} & & - & - & - & $\ldots$ & - & $\ldots$ \\
\hline & & & - & - & - & +++ & - & \\
\hline \multicolumn{2}{|c|}{ strain L(B) } & & - & - & - & $\ldots$ & - & $\ldots$ \\
\hline \multicolumn{3}{|c|}{ C. tropicalis } & & & & & & \\
\hline \multirow{2}{*}{\multicolumn{2}{|c|}{$\begin{array}{l}\text { strain } \mathrm{Ct} 1 \cdot 7 \\
\text { strain } \mathrm{Ct} 2\end{array}$}} & & - & - & - & $\ldots$ & - & $\ldots$ \\
\hline & & & - & - & $\ldots$ & $\ldots$ & - & $\ldots$ \\
\hline \multicolumn{2}{|c|}{ strain $\mathrm{Ct} \mathrm{V}$} & & - & - & $\ldots$ & $\ldots$ & - & $\ldots$ \\
\hline \multicolumn{2}{|c|}{$\begin{array}{l}\text { C. glabrata } \\
\text { C. pseudotropicalis }\end{array}$} & & - & - & $\ldots$ & $\ldots$ & - & $\cdots$ \\
\hline \multicolumn{2}{|c|}{ C. pseudotropicalis } & & - & - & $\cdots$ & $\ldots$ & - & $\ldots$ \\
\hline \multicolumn{2}{|c|}{ C. parapsilosis } & & - & - & $\ldots$ & $\ldots$ & - & $\ldots$ \\
\hline C. krusei & & & - & - & $\ldots$ & $\ldots$ & - & $\ldots$ \\
\hline
\end{tabular}

* Blastospores were obtained either on SDA (S) or after incubation in medium 199 (199).

Fluorescence reaction : $-=$ negative $;+1 \pm=$ faint $;+=$ moderate $;+++=$ strong $; \ldots=$ experiment not performed.

takes place via mannans. Lymphocyte-bound surface antibodies may also react with the protein moieties of mannoproteins thereby establishing linkages with the myelocyte, bound via Con A to the mannan oligosaccharide side chains.

The specificity of MAb 3G6, which is limited in vitro to germ tubes of the homologous strain VW.32, extends in vivo to all of the growth forms of the homologous strain and also to the growth forms of other strains that gave completely negative results in vitro. The expression of the antigens recognised by MAb 3G6, which appear to be preferentially associated with the pathogenic phase, agrees with the concept of $\mathrm{P}$ antigens established earlier (Poulain et al., 1983). It would appear from its sensitivity to heat and pronase that the epitope itself is proteinaceous in nature or is carried by a protein.

$\mathrm{MAb} 3 \mathrm{~B} 7$, which was chosen as representative of the MAbs obtained from the chemical fusion on the other hand, seems to recognise epitopes which are polysaccharide in nature as demonstrated by their thermostability at $80^{\circ} \mathrm{C}$, their extraction by the method of Peat et al. (1961) and their resistance to proteolytic enzymes.

This MAb shares a number of characteristics in common with some of the other MAbs to C. albicans described previously: it is an agglutinating $\operatorname{IgM}$ class immunoglobulin (Brawner and Cutler, 1984; Barbier et al., 1985; Chardes et al., 1986; Miyakawa et al., 1986; Reiss et al., 1986) that recognises cellsurface determinants which are heterogeneous in distribution (Brawner and Cutler, 1984; Miyakawa et al., 1986). The characteristics of MAb 3B7 lie in its strong reactivity against in-vivo growth forms and its ability to differentiate strains of C. albicans independently of serotype. However, previous experience with MAbs has demonstrated the complexity and inter-strain variability in antigen expression by Candida spp. during the cell cycle (Brawner and Cutler, 1984; Hopwood et al., 1986). Further work is necessary, therefore, before it can be concluded that any of the antigens recognised are related to pathogenicity. Nevertheless, the 
Table II. Reactivity of MAb 3B7 against in-vitro and in-vivo growth forms of Candida spp. by IF, direct agglutination and CIE

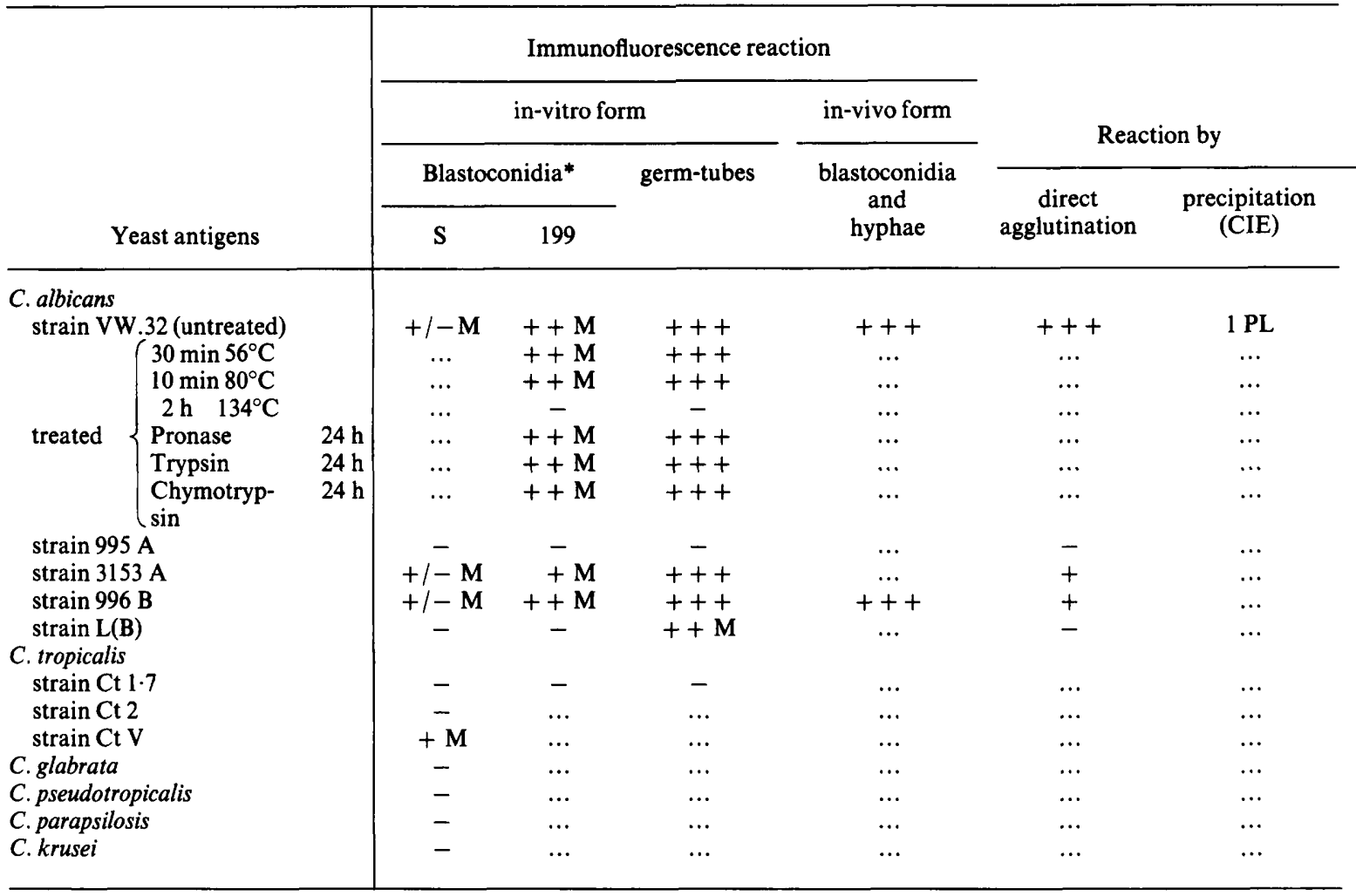

* Blastospores were obtained either on SDA (S) or after incubation in medium 199 (199).

Fluorescence reaction: $-=$ negative $+/-=$ equivocal; $+=$ weak; $++=$ moderate; $+++=$ strong; $M=$ mosaic reaction (a proportion of cells unlabelled) $; \mathrm{PL}=$ precipitin line $;. .=$ experiment not performed.

production of MAbs reacting preferentially with the pathogenic phase of $C$. albicans provides us with a probe for studying such a relationship.

\section{REFERENCES}

Ballou C E 1976 Structure and biosynthesis of the mannan component of the yeast cell envelope. Advances in Microbial Physiology 14: 93-158.

Barbier E, Sarthou O, Le Guern C 1985 Obtention d'un anticorps monoclonal anti-Candida albicans. Bulletin de la Société Française de Mycologie Médicale 14: 13-14.

Brawner D L, Cutler J E 1984 Variability of expression of a cell surface determinant on Candida albicans as evidenced by an agglutinating monoclonal antibody. Infection and Immunity 43: 966-972.

Chardès T, Piechaczyk M, Cavaillès V, Salhi S L, Pau B, Bastide J M 1986 Production and partial characterization of antiCandida monoclonal antibodies. Annales de l'Institut Pasteur, Immunologie 137c: 117-125.

Galfre G, Howe S C, Milstein C, Butcher C W, Howard J C 1977 Antibodies to major histocompatability antigens produced by hybrid cell lines. Nature 226: 550-552.

Hopwood V, Poulain D, Fortier B, Evans G, Vernes A 1986 A
We thank Anne Loyens for technical assistance. We are grateful to the Royal Society, London, and the Centre National de la Recherche Scientifique, Paris, for providing one of us (VH) with an Overseas Research Exchange Fellowship.

monoclonal antibody to a cell wall component of Candida albicans. Infection and Immunity 54: 222-227.

Lo M M S, Tsong T Y, Conrad M K, Strittmatter S M, Hester L D, Snyder H S 1984 Monoclonal antibody production by receptor-mediated electrically induced cell fusion. Nature 310: 792-794.

Miyakawa Y, Kagaya K, Fukazawa Y, Soe G 1986 Production and characterization of agglutinating monoclonal antibodies against predominant antigenic factors for Candida albicans. Journal of Clinical Microbiology 23: 881-886.

Monsigny M, Roche A C, Kieda C 1978 Lectines as tools to study cell surface membranes. In: Structure and functions of biological membranes, molecular aspects. Commission of the European Communities, Brussels, pp 161-234.

Odds F 1985 Morphogenesis in Candida albicans. CRC Critical Reviews in Microbiology 12: 45-93.

Peat S, Whelan W J, Edwards T E 1961 Polysaccharides of bakers yeast. Part IV Mannan. Journal of the Chemical Society 1: 29-34.

Polonelli L, Morace G 1986 Specific and common antigenic 
determinants of Candida albicans isolates detected by monoclonal antibody. Journal of Clinical Microbiology 23: 366-368

Poulain D, Tronchin G, Vernes A, Popeye R, Biguet J 1983 Antigenic variations of Candida albicans in vivo and in vitro. Relationships between $\mathbf{P}$ antigens and serotypes. Sabouraudia 21 : 99-112.

Poulain D, Hopwood V, Vernes A 1985 Antigenic variability of Candida albicans. CRC Critical Reviews in Microbiology 12: 223-270.

Poulain D, Fruit J, Fournier L, Dei Cas E, Vernes A 1986 Diagnosis of systemic candidiasis: application of cocounterimmunoelectrophoresis. European Journal of Clinical Microbiology 5: 427-434.

Reiss E et al. 1986 Monoclonal antibodies against Candida tropicalis mannan : antigen detection by enzyme immunoassay and immunofluorescence. Journal of Clinical Microbiology 24: 796-802.
Smail E H, Jones J M 1984 Demonstration and solubilization of antigens expressed primarily on the surfaces of Candida albicans germ tubes. Infection and Immunity 45: 74-81.

Strockbine N A, Largen M T, Buckley H R 1984 Production and characterization of three monoclonal antibodies to Candida albicans proteins. Infection and Immunity 43: 10121018.

Sundstrom P M, Kenny G E 1984 Characterization of antigens specific to the surface of germ tubes of Candida albicans by immunofluorescence. Infection and Immunity 43: 850-855.

Teissie J, Knutson V P, Tsong T Y, Lane M D 1982 Electricpulse induced fusion of $3 \mathrm{~T} 3$ cells in monolayer culture. Science 216: 537-538.

Winterrowd G E, Cutler J E 1983 Candida albicans-induced agglutinin and immunoglobulin $\mathrm{E}$ responses in mice. Infection and Immunity 41 : 33-38. 